\title{
A Randomized Controlled Trial to Assess the Effectiveness of Vialon ${ }^{\mathrm{TM}}$ Cannula Versus Polytetrafluoroethylene (PTFE) Cannula in Terms of Indwelling Time and Complications in Patients Requiring Peripheral Intravenous Cannulation
}

\author{
Dr. Manju Chhugani ${ }^{1}$, Merlin Mary James ${ }^{2}$, Somibala Thokchom ${ }^{3}$ \\ ${ }^{1}$ RN, RM, MN, MBA, PhD, PG Dip (Human Rights); Principal/Working Dean, Rufaida College of Nursing, Jamia Hamdard, New Delhi, \\ India \\ ${ }^{2,3}$ RN, RM, M.Sc. Nursing; Tutor, Rufaida College of Nursing, Jamia Hamdard, New Delhi, India
}

\begin{abstract}
Intravenous medications are vital in the management of hospitalized patients and complications are associated with them. The objectives were to assess the indwelling time and intravenous complications using Vialon ${ }^{\mathrm{TM}}$ and Polytetrafluoroethylene (PTFE) Peripheral Cannulae. Quantitative experimental research was used. 120 subjects were randomly divided into experimental (Vialon ${ }^{\mathrm{TM}}$ ) and control (PTFE) group. Information sheet, recording sheet and observation checklist were used. The findings revealed Vialon ${ }^{\mathrm{m}}$ Cannulae permitted increased indwelling time (64.5 hours), resulted in less intravenous complications(31.7\%) and less mean phlebitis score (0.23) as compared to PTFE Cannulae (52.9 hours), more intravenous complications(58\%) and more mean phlebitis score (0.48).
\end{abstract}

Keywords: Vialon ${ }^{\mathrm{TM}}$ cannula; Polytetrafluoroethylene (PTFE) cannula; Indwelling time; Intravenous Complications; Effectiveness; Intravenous Cannulation

\section{Text}

Patient care is provided in facilities, which range from highly equipped clinics and technologically advanced university hospitals to front-line units with only basic facilities. Despite progress in public health and hospital care, infections continue to develop in hospitalized patients, and may also affect hospital staff. Many factors promote infection among hospitalized patients, such as decreased immunity among patients, the increasing variety of medical procedures and invasive techniques, creating potential routes of infection ${ }^{1}$.

Among various invasive therapies, intravenous (IV) therapy plays a pivotal role in the management of hospitalized patients. Inpatients frequently receive several IV medications concurrently, and these are commonly delivered with infusion pump systems via IV cannulae. Infections are associated with IV therapy, which may either affect skin around the site of insertion of the cannula or may spread in the bloodstream ${ }^{2}$.

Vost and Longstaff noted that there are several factors that predispose the patients to IV-related infection. These include patient related factors such as presence of infection in other parts of the patient's body, device related factors like catheter material, catheter size, catheter movement, and practice related issues like experience of the personnel, duration of catheterization, composition of infusates, frequency of dressing change, skin preparation, repeated catheterization, nature of the infusion, number of access points and type of dressing ${ }^{3}$.
A study done by Tebbs, Sawyer and Elliott ${ }^{4}$ showed that the smoothness of the surface material of the different cannulae differs substantially. The Vialon cannula has a smoother surface than the Teflon one because of which the former has lower bacterial colonization after one hour of insertion thereby resulting in less chances of infection.

There are limited recent data regarding the impact of different cannulae materials on indwelling times and IV complications. Gaukroger, Roberts and Mannerst 5 conducted a prospective study of the incidence and severity of infusion thrombophlebitis in peripheral IV infusions used for anesthetic and postoperative purposes in 645 patients over a four-month period. A total of 330 polyurethane Vialon and 315 FEP- A Teflon cannulae were used. The result showed that the nature of the cannula was the single most important factor in the incidence and severity of infusion thrombophlebitis, Vialon cannulae being associated with $46 \%$ lower incidence than the Teflon type. Teflon cannulae remained in for 40.8 hours while the Vialon cannulae remained in for 50.9 hours.

Any nurse who commences a prescribed infusion as part of her daily clinical practice needs to undertake specialist training and assessment of competence, which is in line with the organization's protocol in order to minimize the risk. Nurses must recognize the nursing protocol and how they can close the knowledge practice gap. Development of research based protocols for the care of patients may be more beneficial to provide improved health care ${ }^{6}$. IV complications may take several weeks to resolve and during that period it can seriously impair the function in the concerned limb Therefore any reduction in the incidence of 


\section{International Journal of Science and Research (IJSR) \\ ISSN (Online): 2319-7064 \\ Index Copernicus Value (2013): 6.14 | Impact Factor (2014): 5.611}

these complications would be of great benefit to the patients. The objectives of the study were to assess the indwelling time and occurrence of intravenous complications with the use of Vialon ${ }^{\mathrm{TM}}$ Cannula and Polytetrafluoroethylene (PTFE) Cannula.

\section{Materials and Methods}

Two types of peripheral intravenous cannulae were compared under conditions of normal clinical practice. They were Vialon $^{\mathrm{TM}}$ Cannula and PTFE Cannula. PTFE Cannulae made of Polytetrafluoroethylene, manufactured by B Braun were used in this study. It has integrated port allowing injections without an extra needle or risk of needle stick injuries and sharp back cut bevel for minimal puncture trauma. The transparent catheter segments provide confirmation of successful catheter placement when withdrawing the needle. It is Latex-free and PVC-free. (Catalogue Number - Vasofix Braunule 22G - 4268091B, 20G - 4268113B, 18G-4268130B)

The Vialon ${ }^{\mathrm{TM}}$ Cannula manufactured by BD Medical was used in this study. BD Vialon Biomaterial is a unique, proprietary biomaterial, developed over a decade ago, especially for vascular access. BD Vialon biomaterial has been proven to enhance clinical and economic outcomes. The features of Vialon ${ }^{\mathrm{TM}}$ Cannula include ease of insertion, kink resistance, reduced risk of mechanical phlebitis and reduced risk of IV infiltration, all resulting in optimum indwelling time (Catalogue Number , 22G - 393222, 20G $393224,18 \mathrm{G}-393226)$.

Permission was taken from the Institutional Review Board of Jamia Hamdard, New Delhi to conduct the research study. A formal administrative permission was obtained from the administrative authority of Hakeem Abdul Hameed Centenary (HAHC) Hospital to conduct the study.

The subjects requiring IV cannulation were screened based on the inclusion and exclusion criteria and then enrolled for the study. The inclusion criteria included patients who were admitted in the gynaecology wards and ICU's of HAHC Hospital and patients who were available during data collection and the Exclusion Criteria included patients who were admitted in emergency department, dialysis and paediatric ward etc. and patients who were not willing to participate in the study.

The subjects signed a consent form. 120 Subjects of HAHC Hospital, Hamdard Nagar, Jamia Hamdard, New Delhi were selected through purposive sampling technique and were randomized to have either PTFE 18, 20 and 22 gauge cannulae (current standard of care) or Vialon ${ }^{\text {TM }} 18,20$ or 22 gauge cannulae using lottery method (60 per group).

The staff nurses of gynaecology ward and ICU's of same hospital were educated regarding the usage of information sheet, recording sheet, observation checklist and Visual Infusion Phlebitis (VIP) Scale (Table 1) ${ }^{7}$.
Table 1: Visual Infusion Phlebitis (VIP) Scale

\begin{tabular}{|c|c|c|}
\hline APPEARANCE & SCORE & STAGE \\
\hline $\begin{array}{l}\text { IV site appears healthy } \\
\text { Action: observe cannula }\end{array}$ & $\mathbf{0}$ & $\begin{array}{l}\text { No signs of } \\
\text { phlebitis }\end{array}$ \\
\hline $\begin{array}{l}\text { One of the following signs is } \\
\text { evident } \\
\text { - Slight pain near IV site or } \\
\text { - Slight redness near IV site } \\
\text { Action: observe cannula }\end{array}$ & 1 & $\begin{array}{c}\text { Possibly first } \\
\text { signs } \\
\text { of phlebitis }\end{array}$ \\
\hline $\begin{array}{l}\text { aTwo of the following are evident } \\
\text { - Pain at IV site } \\
\text { - Redness } \\
\text { - Swelling } \\
\text { Action: resite cannula }\end{array}$ & 2 & $\begin{array}{l}\text { Early stage of } \\
\text { phlebitis }\end{array}$ \\
\hline $\begin{array}{l}\text { All of the following signs are } \\
\text { evident } \\
\text { - Pain along path of cannula } \\
\text { - Redness around site } \\
\text { - Swelling } \\
\text { Action: resite cannula and consider } \\
\text { Treatment }\end{array}$ & 3 & $\begin{array}{c}\text { Medium stage of } \\
\text { phlebitis }\end{array}$ \\
\hline $\begin{array}{l}\text { All of the following signs are } \\
\text { evident and } \\
\text { extensive } \\
\text { - Pain along path of cannula } \\
\text { - Redness around site } \\
\text { - Swelling } \\
\text { - Palpable venous cord } \\
\text { Action: resite cannula and consider } \\
\text { Treatment }\end{array}$ & 4 & $\begin{array}{l}\text { Advanced stage } \\
\text { of phlebitis or } \\
\text { start of } \\
\text { thrombophlebitis }\end{array}$ \\
\hline $\begin{array}{l}\text { All of the following signs are } \\
\text { evident and } \\
\text { extensive } \\
\text { - Pain along path of cannula } \\
\text { - Redness around site and swelling } \\
\text { - Palpable venous cord } \\
\text { - Pyrexia } \\
\text { Action: initiate treatment/ resite } \\
\text { cannula }\end{array}$ & 5 & $\begin{array}{l}\text { Advanced stage } \\
\text { thrombophlebitis }\end{array}$ \\
\hline
\end{tabular}

Source: Jackson 1998 (Jackson A. Infection Control: A Battle in Vein Infusion Phlebitis. Nursing Times. 1998; 94: 4, 68-71). Permission taken from Ms. Andrew Jackson, IV Nurse Consultant (Andrew.Jackson@rothgen.nhs.uk<mailto:Andrew.Jackso n@rothgen.nhs.uk>).

They were also educated about the standardized procedure of IV cannulation with the use of newer device, Vialon ${ }^{\mathrm{TM}}$ Cannula and assessment of the insertion site for IV complications such as phlebitis, thrombosis, infiltration and extravasation. The cannulae were inserted by the staff nurse on duty in alternating order of patient presentation in the ward or ICU and the details regarding the clinical profileof the each subject related to pre (History of previous disease, History of hospitalization and history of any complication during their previous hospitalization due to cannulation), current (Previous cannulation at the site of insertion,Cannula episode, Material of Cannula used, Gauge of cannula used, Number of attempts while inserting the cannula, Site of Cannulation, Reasons for cannulation and Flushing done with normal saline or not)and post cannulation procedure (Reasons for cannula removal, Moisture present on adhesive while removal and Kinking present on removal, if yes, where was it) were recorded in information sheet. The site of 


\section{International Journal of Science and Research (IJSR) \\ ISSN (Online): 2319-7064}

Index Copernicus Value (2013): 6.14 | Impact Factor (2014): 5.611

cannulation in the upper limb was at the discretion of the staff nurse.

Insertion technique was standardized. The skin was prepared with isopropyl alcoholand the cannula was secured by Tegaderm. The date and time of insertion of the cannula was recorded in the recording sheet.The cannulae were subsequently managed according to the standard clinical practice of the attending nursing staff. The cannulation site was assessed by the investigator- Ms. Merlin Mary James daily until removal. An assessment of the degree of phlebitis was made by observing the IV site for pain, redness, swelling, palpable venous cord and pyrexia using the Visual Infusion Phlebitis (VIP) Scale and other intravenous complications like thrombosis, infiltration and extravasation were also assessed. VIP Scale had a potential score of 0-5, where zero represented no signs of phlebitis and five represented advanced stage of thrombophlebitis.

At the time of device removal the nursing staff were asked to record the date, time and reason for removal. They were also asked whether kinking was present or not and for the presence of moisture on adhesive during removal. Following data collection, an information booklet regarding Standardized Infusion Therapy Protocols was prepared and was disseminated to staff nurses.

All the data were entered in the master sheet in Microsoft Excel. The data were analyzed using descriptive and inferential statistical methods. The demographic variables of the subjects were described using frequencies and percentages. Statistical comparison between categorical data was determined using Chi-Square test or the Fisher - Exact test, whichever was applicable. The mean indwelling time of both cannulae types was assessed. Mean difference between the indwelling time of PTFE cannula and Vialon ${ }^{\mathrm{TM}}$ cannula was calculated by Wilcoxon Rank Sum (Mann-Whitney) Test. ' $Z$ ' Test was applied to find the significant difference between mean phlebitis score of PTFE cannula and Vialon ${ }^{\text {TM }}$ cannula at $\mathrm{p}>0.05$. The cumulative risk for developing phlebitis in each group was compared using a log-rank test on the Kaplan-Meir estimates.

\section{Results}

At the conclusion of the predetermined study period, the performance of 120 cannulae had been assessed. Of the total

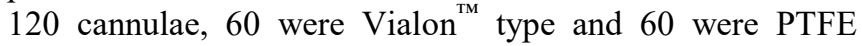
type.
Demographic data like age, gender, educational qualification, etc. of the experimental and control group were compared using Fisher Exact test and Chi-square test and were found to be homogenous. Clinical profile of the subjects like previous history of disease, hospitalization and intravenous complications, present episode of cannulation, gauge of cannula used, number of attempts while inserting the cannula, site of cannulation, reasons for cannulation, whether flushing was done or not, reasons for removal of cannula, presence of moisture on adhesive while cannula removal and whether kinking was present on hub or shaft of cannula on removal of the experimental group and control group were compared using Chi - Square and Fisher's Exact test and were found to be homogenous except for reasons for removal of cannula, presence of moisture on adhesive while cannula removal and whether kinking was present.

Out of 60 subjects in the experimental group, most 19 $(31.7 \%)$ of the subjects' cannulae were removed because intravenous drugs/fluids were terminated, whereas out of 60 subjects in control group, most $35(58 \%)$ of the subjects' cannulae were removed because of intravenous complications.

In experimental group majority of the subjects, 54(90\%) had moisture on adhesive while removal of the cannulae whereas most of the subjects, $35(58.3 \%)$ subjects in the control group had moisture on the cannulae while removal.

Kinking was not present in majority of the subjects' cannulae, i.e. 53(88.3\%) in experimental group, whereas in control group, most of the subjects' cannula, i.e. $35(58.3 \%)$ kinking was present on removal.

The $\mathrm{p}$ values calculated using Chi-Square and Fisher's Exact test were less than 0.05, and were therefore significant. So both the groups were not equal in the abovementioned aspects, (Table 2). 


\section{International Journal of Science and Research (IJSR) \\ ISSN (Online): 2319-7064 \\ Index Copernicus Value (2013): 6.14 | Impact Factor (2014): 5.611}

Table 2: Comparison of Clinical Profile (reasons for cannula removal, moisture present on adhesive and kinking present on cannula removal) of the Subjects in terms of Frequency and Percentage in Experimental and Control group

\begin{tabular}{|c|c|c|c|c|c|c|c|c|c|c|}
\hline \multirow{3}{*}{ S.No. } & \multirow{3}{*}{$\begin{array}{c}\text { Subject } \\
\text { Characteristics }\end{array}$} & \multirow{2}{*}{\multicolumn{2}{|c|}{$\begin{array}{c}\text { Experimental } \\
\operatorname{Group}\left(n_{1}=60\right)\end{array}$}} & \multirow{2}{*}{\multicolumn{2}{|c|}{$\begin{array}{c}\text { Control } \\
\text { Group }\left(n_{2}=60\right)\end{array}$}} & \multirow{3}{*}{$\begin{array}{l}\text { Total } \\
\text { Freq. }\end{array}$} & \multirow{3}{*}{ Total \% } & \multirow{3}{*}{\begin{tabular}{|c|} 
Test Used \\
(Value)
\end{tabular}} & \multirow{3}{*}{ df } & $+n_{2}=120$ \\
\hline & & & & & & & & & & \multirow[t]{2}{*}{ p-value } \\
\hline & & Freq. & $\%$ & Freq. & $\%$ & & & & & \\
\hline \multirow[t]{5}{*}{1.} & $\begin{array}{c}\text { Reasons for } \\
\text { Cannula } \\
\text { Removal: }\end{array}$ & & & & & & & Fisher & 3 & $0.003^{*}$ \\
\hline & & 19 & $31.7 \%$ & 35 & $58 \%$ & 54 & $45.0 \%$ & Exact test & & \\
\hline & $\begin{array}{l}\text { Intravenous } \\
\text { Drugs/Fluids }\end{array}$ & 33 & $55.0 \%$ & 15 & $25 \%$ & 48 & $40.0 \%$ & (5.10) & & \\
\hline & $\begin{array}{c}\text { Terminated } \\
\text { Patient }\end{array}$ & 8 & $13.3 \%$ & 9 & $15 \%$ & 17 & $14.2 \%$ & & & \\
\hline & $\begin{array}{c}\text { Accidental } \\
\text { Removal }\end{array}$ & 0 & $0.0 \%$ & 1 & $2 \%$ & 1 & $0.8 \%$ & & & \\
\hline 2. & \begin{tabular}{|c|} 
Moisture Present \\
on Adhesive while \\
Removal: \\
Yes \\
No
\end{tabular} & $\begin{array}{c}6 \\
54\end{array}$ & $\begin{array}{l}10.0 \% \\
90.0 \%\end{array}$ & $\begin{array}{l}25 \\
35\end{array}$ & $\begin{array}{l}41.7 \% \\
58.3 \%\end{array}$ & $\begin{array}{l}31 \\
89\end{array}$ & $\begin{array}{l}26 \% \\
74 \%\end{array}$ & $\begin{array}{c}\text { Chi- } \\
\text { Square Test } \\
(15.70)\end{array}$ & 1 & $0.00^{*}$ \\
\hline 3. & $\begin{array}{c}\text { Kinking present } \\
\text { on Removal: } \\
\text { Yes } \\
\text { No }\end{array}$ & $\begin{array}{c}7 \\
53\end{array}$ & $\begin{array}{l}11.7 \% \\
88.3 \%\end{array}$ & $\begin{array}{l}25 \\
35\end{array}$ & $\begin{array}{l}41.7 \% \\
58.3 \%\end{array}$ & $\begin{array}{l}32 \\
88\end{array}$ & $\begin{array}{l}27 \% \\
73 \%\end{array}$ & $\begin{array}{c}\text { Chi- } \\
\text { Square Test } \\
(13.80)\end{array}$ & 1 & $0.00^{*}$ \\
\hline
\end{tabular}

" $\mathrm{p} \leq 0.05$, Significant at 0.05 levelof significance

The mean indwelling of both cannulae were obtained using the recording sheet. Mean, median, standard deviation and Z- core of indwelling time of both cannulae were calculated using Wilcoxon- Rank Sum (Mann- Whitney) test. The calculated $\mathrm{Z}$ score (4.70) was more than the table value of $\mathrm{Z}$ $=1.96$ at 0.05 level of significance which indicates that there was a significant difference between mean indwelling times of the two groups. This indicates that Vialon ${ }^{\text {TM }}$ cannulae $(64.5$ hours) have statistically been shown to have longer indwelling time than PTFE cannula (52.9 hours), (Table 3).

Table 3: Comparison of Mean Indwelling Time of Cannulae

\begin{tabular}{|c|c|c|c|c|}
\hline \multicolumn{2}{|c|}{ in Experimental and Control Group } \\
\hline GROUP & MEAN \pm S.D. & $d f$ & $\begin{array}{c}\text { Wilcoxon- } \\
\text { Rank Sum } \\
\text { Test } \\
\text { Z-Score }\end{array}$ & $p$-value \\
\hline $\begin{array}{c}\text { Experimental Group } \\
(\mathrm{n}=60)\end{array}$ & $64.5 \pm 12.8$ & 118 & $\mathbf{4 . 7 0}^{*}$ & $0.00^{*}$ \\
\hline $\begin{array}{c}\text { Control Group } \\
(\mathrm{n}=60)\end{array}$ & $52.9 \pm 12.3$ & & \\
\hline
\end{tabular}

\section{$* \mathbf{p} \leq \mathbf{0 . 0 5}$, Significant at 0.05 level of significance}

Frequency and Percentage of the occurrence of Intravenous Complications in Experimental and Control Group was computed which showed that out of 60 subjects in experimental group (Vialon ${ }^{\mathrm{TM}}$ ), only 19 (31.67\%) developed IV complications; whereas out of 60 subjects in control group (PTFE), 35(58.33\%) developed IV complications, (Figure 1).

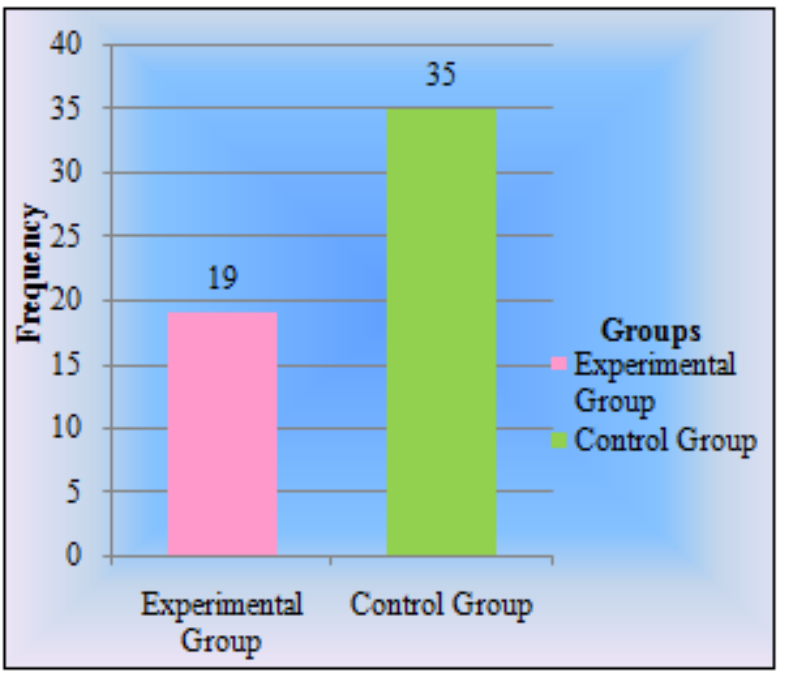

Figure 1: Bar Diagram illustrating Frequency of the Occurrence IV Complications in Experimental and Control Group

The mean phlebitis score of both cannulae were obtained using the observation checklist. Mean, standard deviation and Z- value, of phlebitis score of both cannulae were calculated using $Z$ Test. The calculated $Z$ value (3.19) at 0.05 level of significance was greater than the table value of $\mathrm{Z}$ (1.96), which indicates that there was a significant difference between mean phlebitis score of the two groups. This indicates that Vialon ${ }^{\mathrm{TM}}$ cannula has shown to have a statistically lower mean phlebitis score than PTFE cannula, (Table 4). 


\section{International Journal of Science and Research (IJSR) \\ ISSN (Online): 2319-7064 \\ Index Copernicus Value (2013): 6.14 | Impact Factor (2014): 5.611}

Table 4: Comparison of Mean Phlebitis Score in Experimental and Control Group

\begin{tabular}{|c|c|c|c|c|}
\hline GROUP & MEAN \pm S.D. & $d f$ & Z-Value & -value \\
\cline { 1 - 2 } $\begin{array}{c}\text { Experimental Group } \\
(\mathrm{n}=60)\end{array}$ & $0.23 \pm 0.42$ & 118 & $3.19^{*}$ & $0.003^{* *}$ \\
\cline { 1 - 2 } $\begin{array}{c}\text { Control Group } \\
(\mathrm{n}=60)\end{array}$ & $0.48 \pm 0.44$ & & & \\
\hline
\end{tabular}

$* \mathrm{Z}(118)=1.96 * \mathrm{p} \leq \mathbf{0 . 0 5}$, Significant at 0.05 level
Frequency of subjects according to the days the cannulae were in place (in situ) in experimental and control group was computed. Out of the 60 subjects in the experimental group, there were no subjects that retained cannulae in situ for less than 1.5 days; the lowest number of days that the cannulae were present in situ was 2 days, with the highest number of subjects (25) retaining cannulae in situ for 3 days. In the control group, 7 subjects had cannulae in situ for less than 1.5 days, with the highest number of subjects (21) retaining cannulae in situ for 2 days, (Figure 2).

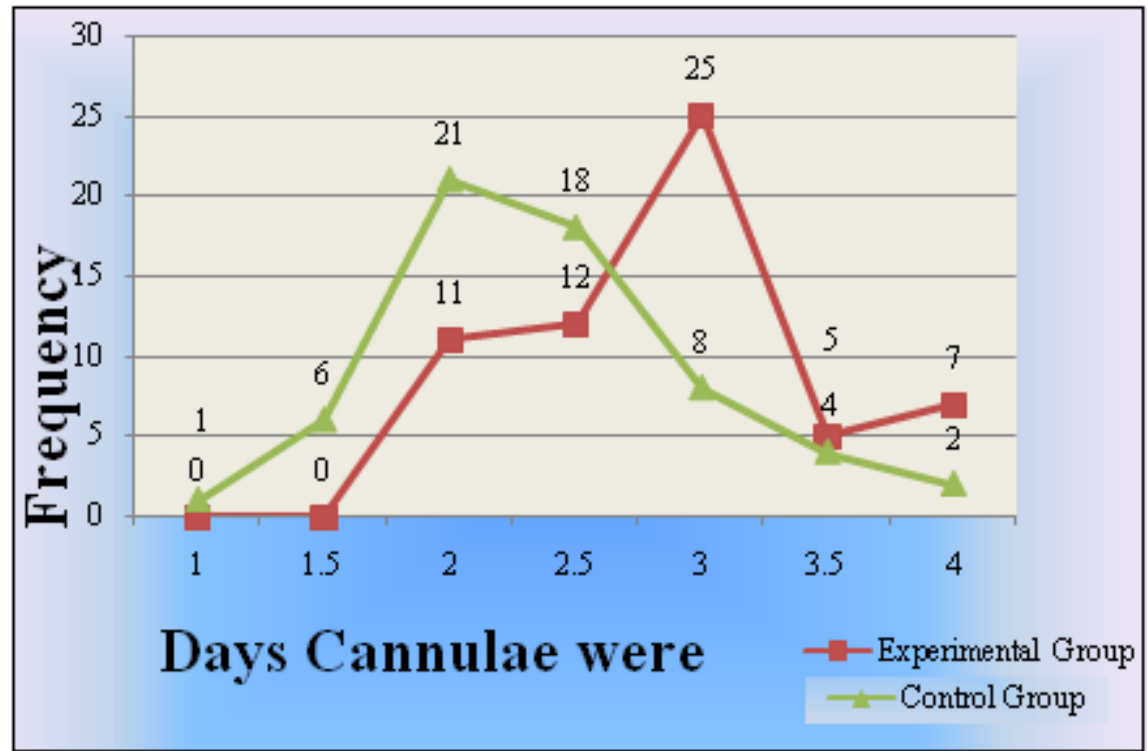

Figure 2: Line Graph depicting Frequency of Subjects according to the Days Cannulae were In Situ in Experimental and Control Group

The day wise cumulative risk (survival analysis) for developing phlebitis in experimental and control group was compared using a log rank test on the Kaplan - Meir estimates. There was influence of cannula material on the incidence of phlebitis, which increased, with extended placement of cannula. Survival analysis by log-rank test showed a reduced risk for phlebitis with Vialon ${ }^{\mathrm{TM}}$ cannula, (Table 5, Figure 3).

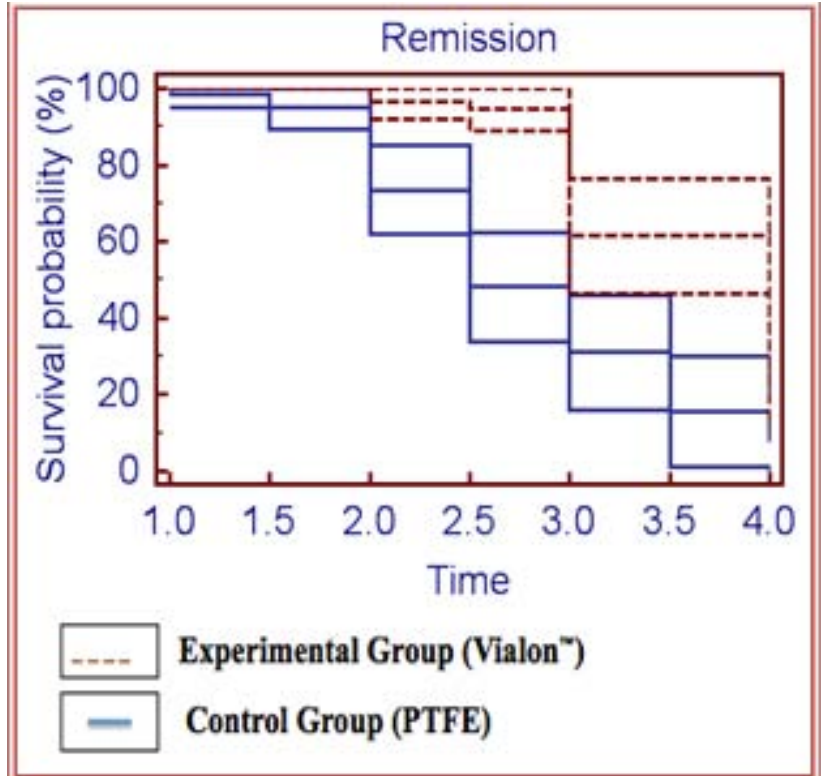

Figure 3: Line Diagram depicting the Cumulative Risk for Phlebitis in Experimental and Control Group

\section{Discussion and Conclusion}

The study demonstrated a marked difference between the performances of the two different cannula materials in terms of indwelling time and occurrence of IV complications. The literature contains a multitude of factors said to affect the likelihood of IV infusion vein developing an intravenous complication, such as type of infusates, catheter material and size, etc. influence a patient's risk for development of phlebitis. As this condition is a common, painful and troublesome experience, it worthwhile to re-examine the influence of catheter material for development of IV complications. Evidence is accumulating that catheter material plays an important role in the pathogenesis of intravenous complications. In the present study, the findings showed that PTFE Cannulae were more often removed because of intravenous complications $(58 \%)$ than were the Vialon $^{\text {TM }}$ Cannula (31.7\%). Vialon ${ }^{\text {TM }}$ Cannulae had statistically lower mean phlebitis scores $(0.23)$ compared to PTFE Cannulae (0.48).

The study found that Vialon ${ }^{\mathrm{TM}}$ Cannulae had an increased indwelling time (64.5 hours) as compared to PTFE Cannulae with a reduced indwelling time (52.9 hours). The duration of cannulation was clearly associated with the incidence of phlebitis, i.e. it was frequently observed that the longer the cannula is left in situ, the more likely phlebitis is to develop. The study findings revealed the influence of cannula material on the increased incidence of phlebitis with extended placement of cannula. In addition, survival

\section{Volume 4 Issue 12, December 2015}




\section{International Journal of Science and Research (IJSR) \\ ISSN (Online): 2319-7064 \\ Index Copernicus Value (2013): 6.14 | Impact Factor (2014): 5.611}

analysis by log-rank test showed a reduced risk for phlebitis with Vialon ${ }^{\text {TM }}$ cannula. This underscores the need for the staff nurses to be educated in the use of VIP Scale [Visual Infusion Phlebitis (VIP) scale is a tool recommended by the Royal College of Nursing and this scale was first developed by Jackson in 1998. The VIP scale has been shown to be a valid and reliable measure for determining when an intravenous catheter should be removed (Gallant and Schultz, 2006). The VIP score is recommended in the Infusion Nursing Standards of Practice (INS, 2011)], for the early identification and prompt management of phlebitis.

Vialon $^{\text {TM }}$ cannula can be considered as a safe option. Research evidence suggests that the use of Vialon ${ }^{\mathrm{TM}}$ cannula has resulted in lower incidence of phlebitis and longer indwelling time. Hence, this device could be introduced into the routine practice, as infusion thrombophlebitis may take several weeks to resolve and during that period this can seriously impair the function in the concerned limb. Any reduction in its incidence would be of great benefit to the patients.

Short term courses can be organized to update the staff nurses with knowledge on identification of IV complication and keep them abreast with the knowledge on usage of newer devices of cannulation like Vialon ${ }^{\mathrm{TM}}$ cannula which has the safety mechanism as well as lowered risk for developing phlebitis coupled with longer indwelling time.

Reduction in IV complications contributes to decline in the hospital acquired (nosocomial) infections rate which indirectly hoists the reputation of the hospital and is a value added benefit to nursing care rendered to the patient making it an aspect of emulation for other hospitals thereby setting the hospital as a benchmark and quality indicator for patient care. Therefore, health care team including doctors and nurses should be sensitized and made aware about the benefits of the newer devices.

Strategies and newer approaches can be incorporated for the formulation of standardized infusion therapy protocols to undertake peripheral cannulation by providing information on how to improve venous access and choosing a suitable vein and cannula and to provide a practical guide on how to insert a cannula safely as well as prevention and management of infusion therapy complications during and following the insertion. This will enable the staff nurses to identify their responsibilities while performing intravenous cannulation.

Most of the studies including the present study were focused on local complications like phlebitis, infiltration, thrombosis and hematoma through assessment of the VIP Scale and did not investigate occurrence of other systemic complications. Further research can be done to develop a standardized scale for measuring other IV complications. In conclusion, Vialon $^{\mathrm{TM}}$ cannulae were significantly less likely to develop IV complications and permitted longer indwelling time than the PFTE Cannulae.

\section{Acknowledgement}

The authors wish to acknowledge Dr. Jayant Giri, Manager, Clinical Initiatives, BD India Pvt. Ltd. and Dr. Huma Tahir,
Clinical Resource Consultant, BD India Pvt. Ltd. for their valuable advice and helpful suggestions, which played an important role in completion of this work. We also like to express our sincere thanks to all patients and Staff Nurses who enthusiastically participated in carrying out the project.

\section{References}

[1] Ducel G, Fabry J, Nicolle. Prevention of HospitalAcquired Infections - A Practical Guide. Geneva. WHO; 2002.

[2] Wilson J. Infection Control in Clinical Practice. Philadelphia: Elsevier Limited; 2006.

[3] Vost $\mathbf{J}$ and Longstaff V. Infection Control and Related Issues in Intravascular Therapy. British Journal of Nursing. 1997; 6(15): 846-852.

[4] Tebbs SE, Sawyer A, Elliott TSJ. Influence of Surface Morphology on Invitro Bacterial Adherence to Central Venous Catheter. British Journal of Anaesthesiology. 1994; 72: 587-591.

[5] Gaukroger PB, Roberts JG, Mannerst TA. Infusion Thrombophlebitis: A Prospective Comparison of 645 Vialon and Teflon Cannulae in Anaesthetic and Postoperative Use. 1988; 16 (3): 265-271.

[6] Dawn B. Clinical Guideline for Peripheral Intravenous Cannulation, 2 Edition. South Gloucestershire Primary Care Trust, London. 2007: 1-11.

[7] Jackson A. Infection Control: A Battle in Vein Infusion Phlebitis. Nursing Times. 1998; 94: 4, 68-71. 